\title{
Payments for care at private for-profit and private not-for-profit hospitals: a systematic review and meta-analysis
}

\author{
P.J. Devereaux, Diane Heels-Ansdell, Christina Lacchetti, Ted Haines, Karen E.A. Burns, \\ Deborah J. Cook, Nikila Ravindran, S.D. Walter, Heather McDonald, Samuel B. Stone, \\ Rakesh Patel, Mohit Bhandari, Holger J. Schünemann, Peter T.-L. Choi, Ahmed M. Bayoumi, \\ John N. Lavis, Terrence Sullivan, Greg Stoddart, Gordon H. Guyatt
}

ß See related article page 1814

Fast-tracked article

Abstract

Background: It has been shown that patients cared for at private for-profit hospitals have higher risk-adjusted mortality rates than those cared for at private not-for-profit hospitals. Uncertainty remains, however, about the economic implications of these forms of health care delivery. Since some policy-makers might still consider for-profit health care if expenditure savings were sufficiently large, we undertook a systematic review and meta-analysis to compare payments for care at private forprofit and private not-for-profit hospitals.

Methods: We used 6 search strategies to identify published and unpublished observational studies that directly compared the payments for care at private for-profit and private not-forprofit hospitals. We masked the study results before teams of 2 reviewers independently evaluated the eligibility of all studies. We confirmed data or obtained additional data from all but 1 author. For each study, we calculated the payments for care at private for-profit hospitals relative to private notfor-profit hospitals and pooled the results using a random effects model.

Results: Eight observational studies, involving more than 350000 patients altogether and a median of 324 hospitals each, fulfilled our eligibility criteria. In 5 of 6 studies showing higher payments for care at private for-profit hospitals, the difference was statistically significant; in 1 of 2 studies showing higher payments for care at private not-for-profit hospitals, the difference was statistically significant. The pooled estimate demonstrated that private for-profit hospitals were associated with higher payments for care (relative payments for care 1.19, 95\% confidence interval 1.07-1.33, $p=0.001$ ).

Interpretation: Private for-profit hospitals result in higher payments for care than private not-for-profit hospitals. Evidence strongly supports a policy of not-for-profit health care delivery at the hospital level.

CMAJ 2004;170(12):1817-24
$\mathrm{S}$ eparating issues of funding (i.e., who pays for health care) and delivery (i.e., who owns and administers the institutions providing care) helps to inform debates about health care systems. Funding for health care can come through private sources, primarily administered through insurance companies, or through public payment, by governments using tax dollars. Care can be delivered at private for-profit institutions that are owned by investors; private not-for-profit institutions that are owned by communities, religious organizations or philanthropic groups; or public health care institutions owned and administered by the government.

Canadian hospitals are publicly funded. In terms of delivery, although they are commonly referred to as public institutions, Canadian hospitals are almost all owned and operated by private not-for-profit organizations. ${ }^{1}$ Canadian policy-makers continue to consider an expansion of private for-profit health care delivery, including private for-profit hospitals. ${ }^{1}$

We have previously demonstrated higher risk-adjusted death rates among patients receiving care at private forprofit hospitals than among patients at private not-forprofit hospitals in a comprehensive systematic review. ${ }^{2}$ Uncertainty remains, however, about the economic implications of these forms of health care delivery. Studies evaluating the economics of health care delivery usually evaluate costs, charges or payments for care. ${ }^{3}$ From the perspective of a service provider, costs represent how much the provider paid to provide care, charges represent how much the provider billed the payer, and payments represent how much the provider received for the care received. In the context of publicly funded health care, the central policy question is how much government will pay for care delivered by private for-profit versus private notfor-profit providers. We therefore undertook a systematic 
review and meta-analysis to address the following question: is there a difference in payments for patient care received at private for-profit compared with private not-forprofit hospitals?

\section{Methods}

We included published and unpublished observational studies and randomized controlled trials that directly compared payments for care at private for-profit and private not-for-profit hospitals. Because we required an estimate of variance to determine the precision of the estimate of the relative payments and to combine studies in our meta-analysis, we excluded from the quantitative meta-analysis studies that did not report (or whose authors could not provide) an estimate of variance for the payments.

Strategies to identify studies included an electronic search of 11 bibliographical databases; consultation with experts; review of our own files; review of reference lists from articles fulfilling our eligibility criteria; use of the "see related articles" feature in PubMed (in June 2003) for publications fulfilling our eligibility criteria; and use of SciSearch (in June 2003) for publications fulfilling our eligibility criteria.

A medical librarian used all the studies of which we were initially aware to identify medical subject-heading terms and key words for the search. In each database, the librarian iteratively refined the search strategy through testing several search terms and incorporating new search terms as new relevant citations were identified. The search included the following databases: EMBASE (1980-2001), MEDLINE (1966-2001), HealthSTAR (19752001), CINAHL (1982-2001), BIOETHICSLINE (1973-2000), Wilson Business Abstracts (1997-2001), EconLit (1969-2001), Cochrane Library (2001, issue 3), Dissertation Abstracts Ondisc (1861-2001), ABI/Inform (1970-2001) and NTIS (National Technical Information Service) (1964-2002). The database search strategies are described in online Appendix 1 (www.cmaj.ca/cgi /content/full/170/12/1817/DC1).

Our 6 search strategies identified 7535 unique citations. Ten teams of 2 people independently screened the titles and abstracts of each citation and identified all citations that might contain a comparison of interest. This process yielded 788 full-text publications, identified by either screener, which we selected for full review (Fig. 1).

We masked the results by blacking them out in the tables and text of all publications selected for full review. To determine eligibility, 10 teams of 2 reviewers independently evaluated masked articles that they had not assessed during the screening process. The kappa value for agreement on article eligibility was 0.75 . The consensus process to resolve disagreements required reviewers to discuss the reasoning for their decisions; in all cases, a realization of error by 1 reviewer completed the process. When both reviewers were uncertain as to whether a study was eligible, we contacted the author to clarify information.

Two reviewers independently abstracted the following data from all studies meeting eligibility criteria: sampling method, source of data, case mix, type of hospitals evaluated (e.g., general acute care, psychiatric), dates when data collection was initiated and completed, duration of patient follow-up, number of hospitals and patients evaluated, patient source of payment (e.g., public, private insurance) and potential confounders adjusted for in the analyses. Reviewers resolved disagreements by consensus using the process described above. Our overall agreement was $89 \%$ for the data abstraction. We attempted to contact the authors of all eligible studies to obtain or confirm data.

Before undertaking this systematic review we considered studies methodologically strong if they adjusted for the following factors: age, sex, ethnicity, income, education, primary diagnosis (case mix), comorbid conditions, severity of illness, market competition (the concentration of hospitals in a region), patient source of payment and hospital teaching status. We also considered analyses to be overadjusted if investigators adjusted for a variable that was under the control of hospital administrators, could vary by profit status and could possibly affect payments for care. For example, we considered an analysis overadjusted if it adjusted for staffing levels or the skill level of the hospital staff. Our quality assessment of studies included whether the study appropriately adjusted for any of the factors listed above and avoided overadjustment.

Before the analysis, we specified several hypotheses to explain variability in the direction and magnitude of effect across studies. We hypothesized that the effect size may differ depending on whether the hospitals evaluated were specialty or general hospitals; whether the payments for care were per discharge or per day; whether the payments for care were related to the hospital stay or included a period of time after hospital discharge; whether the analysis adjusted for potential confounders or was unadjusted; whether the patient source of payment was public or mixed (public and private); whether the patient population was adult or pedi-

6 strategies employed to identify relevant articles

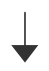

7535 citations identified for initial screening of titles and abstracts (low threshold for retrieval)

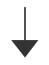

788 potentially eligible studies retrieved

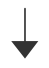

Potentially eligible studies masked (results obscured with black marker)

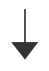

Masked studies assessed for eligibility (studies reviewed in duplicate and consensus process used)
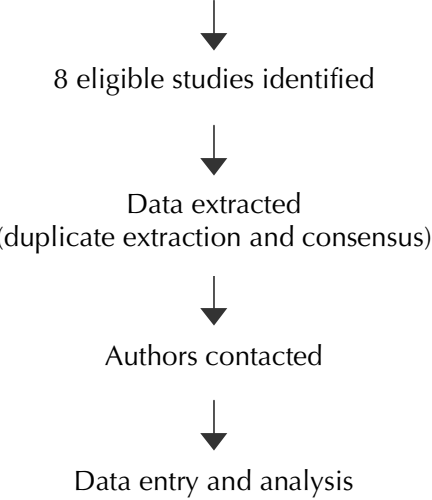

Fig. 1: Methodological steps of our systematic review. 
atric; and whether the data collection occurred before 1984 (when US Medicare switched from reimbursement based on the costs of care to reimbursement based on a patient's diagnosis).

For each study we computed the relative payments for care at private for-profit hospitals relative to private not-for-profit hospitals (see online Appendix 2 at www.cmaj.ca/cgi/content/full/170/12 /1817/DC2). If a study reported 2 or more analyses with variance data, we included the adjusted analysis over an unadjusted analysis, and the analysis based on payments per discharge over that based on payments per day. We pooled these relative payments for care using a random effects model ${ }^{4}$ by weighting the natural logarithm of the relative payments by the inverse of their variances. Relative to the fixed effects model, the random effects model allows for between-study variation in the effect measure in addition to withinstudy variation. The random effects model generally results in wider confidence intervals than the fixed effects model. Although the random effects model still gives greater weight to studies with smaller variance than to studies with larger variance, the relative weight assigned to large studies is reduced compared with the weight assigned to those studies in the fixed effects model.

We calculated an $\mathrm{I}^{2}$ as a measure of heterogeneity for the main analysis. An $\mathrm{I}^{2}$ value represents the percentage of total variation across studies that is caused by heterogeneity rather than by chance. We considered a low $\mathrm{I}^{2}$ value as $25 \%$ or lower and a high $\mathrm{I}^{2}$ value as $75 \%$ or higher. ${ }^{5}$ We conducted a visual examination of funnel plots for evidence of publication bias. ${ }^{6}$

The Hamilton Health Sciences Research Ethics Board in Hamilton, Ontario approved the study protocol.

\section{Results}

We identified 8 publications of observational studies that met our eligibility criteria. ${ }^{7-14} \mathrm{We}$ also identified 10 publications that we believed might be eligible but which required additional data from the authors. We were able to contact 9 of the 10 authors and to confirm that 6 of these studies had no measure of variance, 3 grouped private notfor-profit and public not-for-profit hospitals together and the authors either no longer had the data or could not re- run the analyses excluding the public hospitals, and 1 study had data on charges for care and did not have data on payments for care; these 10 studies were excluded from our systematic review (Table 1). ${ }^{15-24}$ All 10 excluded studies found higher payments or charges for care at private forprofit hospitals than at not-for-profit hospitals; in 6 of the 10 , the differences were statistically significant. ${ }^{15-17,21,22,24}$

Table 2 presents the study characteristics and Table 3 the study methodology of the 8 observational studies included in our systematic review. We obtained or confirmed data with the investigators for 7 studies; the sole author of the remaining study had died. ${ }^{8}$ All studies were conducted in the United States and included data from 1980 until Dec. 31, 1994. The 8 studies included over 350000 patients and assessed a median of 324 hospitals per study.

Our quality assessment of studies revealed that 6 of the 8 studies appropriately adjusted or matched cases for many important determinants of payment for care (e.g., case mix). For 2 studies the authors were unable to provide an estimate of variance for their adjusted analyses, which we required to combine studies in our meta-analysis; instead, we report their unadjusted analyses for which there was an estimate of variance. ${ }^{79}$ The statistical significance of the findings of these 2 studies did not change between the unadjusted and adjusted analyses., ${ }^{7,9}$

Five of the 8 studies showed statistically significant higher payments for care at private for-profit hospitals,, $11-14$ 1 showed statistically significant lower payments for care at private for-profit hospitals, ${ }^{8} 1$ showed a nonsignificant trend toward higher payments for care at private for-profit hospitals ${ }^{7}$ and 1 showed a nonsignificant trend toward lower payments for care at private for-profit hospitals (Fig. 2). ${ }^{10}$ Funnel plots did not suggest publication bias.

Our primary meta-analysis demonstrated that private forprofit hospitals were associated with higher payments for care (relative payments for care $1.19,95 \%$ confidence interval $[\mathrm{CI}] 1.07-1.33, p=0.001)$. There was large heterogeneity

Table 1: Excluded studies initially thought to be potentially eligible

\begin{tabular}{ll}
\hline Problems that precluded study inclusion & \multicolumn{1}{c}{ Efforts to resolve problems } \\
\hline $\begin{array}{l}\text { Six studies evaluated payments for care in PFP } \\
\text { and PNFP hospitals, but no measures of }\end{array}$ & $\begin{array}{l}\text { Five authors were unable to provide the data, }{ }^{15,16,18-20} \text { and we were unable to } \\
\text { contact } 1 \text { author. }{ }^{17} \text { Two publications reported statistically significant higher } \\
\text { variance were available }{ }^{15-20}\end{array}$ \\
$\begin{array}{l}\text { payments for care in PFP hospitals, }{ }^{15,16} 1 \text { publication reported statistically } \\
\text { significant higher payments for care in PFP hospitals for } 11 \text { of the } 13 \text { DRGs } \\
\text { evaluated, }{ }^{17} 1 \text { publication reported a trend toward higher payments for care in }\end{array}$ & $\begin{array}{l}\text { PFP hospitals, }{ }^{18} \text { and } 2 \text { publications did not report statistical analyses but } \\
\text { demonstrated higher payments for care in PFP hospitals }{ }^{19,20}\end{array}$
\end{tabular}

Three studies evaluated payments for care in PFP and NFP hospitals, but the NFP hospitals were a mixture of public and private NFP hospitals ${ }^{21-23}$

One study evaluated charges for care at PFP and PNFP hospitals ${ }^{24}$
All 3 authors were contacted but were unable to provide the data to compare the PFP and PNFP hospitals. Two publications reported statistically significant higher payments for care in PFP hospitals, ${ }^{21,22}$ and 1 publication did not report statistical findings but demonstrated higher payments for care in PFP hospitals ${ }^{23}$

The author was contacted but was unable to provide payment data. This study reported statistically significant higher charges for care in PFP hospitals $^{24}$

Note: PFP = private for-profit, PNFP = private not-for-profit, NFP = not-for-profit, DRG = diagnosis related group. 
across the study results $\left(I^{2}=90 \%\right)$. The lone study, by Kauer, that showed statistically significant higher payments for care at private not-for-profit hospitals compared hospitals owned by not-for-profit organizations but run by a for-profit firm with hospitals owned and operated by private for-profit organizations. ${ }^{8}$ Because this study design is different than that of the other studies, we undertook a heterogeneity test that evaluated the difference between Kauer's estimate of payments for care (relative payments for care 0.93, 95\% CI 0.88-0.99) and the estimate from the other studies (relative payments for care 1.24, 95\% CI 1.11-1.39), and this test was statistically significant $(p=0.048)$. Even without Kauer's study, large heterogeneity across the study results $\left(\mathrm{I}^{2}=86 \%\right)$ persisted. Only 1 of our predefined hypotheses (specialty versus general hospitals) helped to explain some of the persistent heterogeneity ( $p=0.02$ for the difference between these subgroup summary estimates). Pooled estimates from both the 3 studies that evaluated specialty hospitals and the 5 studies that evaluated general hospitals showed higher payments for care at private for-profit hospitals (relative payments for care $1.48,95 \%$ CI 1.15-1.89, and 1.11, $95 \%$ CI 1.00-1.23, respectively).

The 2 studies with the most extensive adjustment for potential confounders - the study by Sloan and associates ${ }^{12}$ and the study by Keeler and associates ${ }^{13}$ - reported statistically significant higher payments for care at the private forprofit hospitals than at the private not-for-profit hospitals (relative payments for care 1.51, 95\% CI 1.17-1.94, and $1.13,95 \%$ CI 1.09-1.16, respectively).

\section{Interpretation}

We identified 8 observational studies that compared payments for care at private for-profit and private not-forprofit hospitals. These studies altogether involved more than 350000 patients and included a median of 324 hospitals each. Five of the studies and our pooled analysis demonstrated statistically significant higher payments for care at private for-profit hospitals than at private not-forprofit hospitals.

Our systematic review has several strengths. We undertook a comprehensive search using 6 strategies to identify studies for our review, masked study results before determining study eligibility, conducted eligibility decisions and data abstraction in duplicate and demonstrated a high degree of agreement. For 7 of the 8 studies the investigators provided or confirmed data.

Our systematic review has several limitations. We did not identify any randomized controlled trials. It is unlikely that patients will ever be randomly assigned to private forprofit and private not-for-profit health care delivery systems. Therefore, the strongest realistic design for addressing our question is an observational study.

The main limitation of observational data is the potential for confounding. Six of the 8 observational studies adjusted for potential confounders. The statistical significance of the findings within the 2 studies for which we present the unadjusted analyses did not vary between the unadjusted and adjusted analyses. ${ }^{7,9}$ The 2 studies with the most extensive adjustment for potential confounders both reported statistically significant higher payments for care at the private for-profit hospitals (relative payments for care 1.51 and 1.13). ${ }^{12,13}$ For example, the study by Sloan and associates adjusted for age, sex, education, ethnicity, marital status, income, community living, number of activities of daily living, cognitive awareness, bladder/bowel control, comorbidity, primary diagnosis at index admission, market characteristics (population per square mile, Herfindahl index, Medicare hospital wage index, Health Maintenance Organization market share, hospital beds per 100 popula-

\begin{tabular}{|c|c|c|c|c|c|}
\hline Study* & Type of hospital & $\begin{array}{l}\text { Sources of } \\
\text { payments }\end{array}$ & $\begin{array}{l}\text { Date when data } \\
\text { collection was } \\
\text { initiated }\end{array}$ & $\begin{array}{l}\text { Date when data } \\
\text { collection was } \\
\text { completed }\end{array}$ & $\begin{array}{l}\text { Follow-up period } \\
\text { for individual } \\
\text { patients }\end{array}$ \\
\hline Van Ness ${ }^{7}$ & General acute care & $\begin{array}{l}\text { Public and } \\
\text { private }\end{array}$ & 01/01/1980 & $31 / 12 / 1981$ & In hospital \\
\hline Kauer $^{8}$ & General acute care & $\begin{array}{l}\text { Public and } \\
\text { private }\end{array}$ & 01/01/1981 & $31 / 12 / 1984$ & In hospital \\
\hline Dickey $^{9}$ & Mixed $\dagger$ & Private & 01/07/1985 & 30/06/1987 & In hospital \\
\hline Dranove et $\mathrm{al}^{10}$ & General acute care & $\begin{array}{l}\text { Public and } \\
\text { private }\end{array}$ & Fiscal year 1983 & Fiscal year 1992 & In hospital \\
\hline McCue et $\mathrm{al}^{11}$ & Psychiatric acute care & $\begin{array}{l}\text { Public and } \\
\text { private }\end{array}$ & Fiscal year 1986 & $\begin{array}{l}\text { Fiscal period } \\
\text { ending } 1990\end{array}$ & In hospital \\
\hline Sloan et $\mathrm{al}^{12}$ & General acute care & Medicare & 01/01/1983 & $31 / 12 / 1994$ & $6 \mathrm{mo}$ \\
\hline Keeler et $\mathrm{al}^{13}$ & General acute care & $\begin{array}{l}\text { Medicaid } \\
\text { and private }\end{array}$ & 01/01/1986 & $31 / 12 / 1994$ & In hospital \\
\hline McCue et $\mathrm{al}^{14}$ & Rehabilitation & $\begin{array}{l}\text { Public and } \\
\text { private }\end{array}$ & Fiscal year 1989 & $\begin{array}{l}\text { Fiscal year } \\
\text { ending } 1992\end{array}$ & In hospital \\
\hline
\end{tabular}

*The studies are in chronological order by midpoint of the data collection period.

†Mixed = general, major teaching, free-standing psychiatric or free-standing substance abuse. 


\section{Table 3: Methodology of studies included in the systematic review}

\begin{tabular}{|c|c|c|c|c|}
\hline Study* & Sampling method & Data source & Case mix & $\begin{array}{l}\text { Factors controlled for } \\
\text { in the analysis }\end{array}$ \\
\hline Van Ness ${ }^{7}$ & $\begin{array}{l}\text { All acute care general hospitals that } \\
\text { reported annual utilization and financial } \\
\text { data to the California HFC. Excluded } \\
\text { hospitals: psychiatric, children's, } \\
\text { university teaching, state, government, } \\
\text { Kaiser Foundation, dental, and hospitals } \\
\text { managed under contract by for-profit or } \\
\text { not-for-profit chains }\end{array}$ & $\begin{array}{l}\text { California HFC } \\
\text { Commission, HCFA }\end{array}$ & No restriction & Unadjusted \\
\hline Kauer $^{8}$ & $\begin{array}{l}\text { Hospitals randomly selected from all } \\
\text { domestic owned or contract managed } \\
\text { HCA hospitals that were acute care } \\
\text { medical/surgical hospitals. Excluded } \\
\text { hospitals: those with missing critical data, } \\
\text { specialty hospitals, flagship hospitals and } \\
\text { hospitals that were with the HCA system } \\
\text { for }<3 \mathrm{yr}\end{array}$ & $\begin{array}{l}\text { Audited year-end } \\
\text { financial statements, } \\
\text { HCA operating } \\
\text { indicators reports, and } \\
\text { Federal Register }\end{array}$ & No restriction & $\begin{array}{l}\text { Case mix, no. of beds, occupancy, wage } \\
\text { index, ancillary services, year }\end{array}$ \\
\hline Dickey $^{9}$ & $\begin{array}{l}\text { Psychiatric and substance abuse } \\
\text { admissions of employees and their } \\
\text { dependents }<65 \mathrm{yr} \text { old from } 2 \text { large } \\
\text { national corporations with generous } \\
\text { indemnity health plans that included } \\
\text { nondiscriminatory unlimited inpatient } \\
\text { mental health benefits }\end{array}$ & $\begin{array}{l}\text { Paid claims data from } \\
\text { health plans }\end{array}$ & $\begin{array}{l}\text { Psychiatric and } \\
\text { substance abuse } \\
\text { disorders }\end{array}$ & Unadjusted \\
\hline Dranove et $\mathrm{al}^{10}$ & $\begin{array}{l}\text { Private short-term hospitals in California } \\
\text { that reported data to the California OSHPD } \\
\text { and that had enough Medicaid patients to } \\
\text { allow for reliable measures of service levels } \\
\text { during fiscal years } 1983 \text { and } 1992\end{array}$ & $\begin{array}{l}\text { Hospital disclosure files } \\
\text { and discharge data files } \\
\text { of the California } \\
\text { OSHPD }\end{array}$ & No restriction & Case mix \\
\hline McCue et $\mathrm{al}^{11}$ & $\begin{array}{l}\text { Short-term psychiatric hospitals reported } \\
\text { by the national association of Private } \\
\text { Psychiatric Hospitals in 1989; matched by } \\
\text { profit status according to location in same } \\
\text { county, standard metropolitan statistical } \\
\text { area or wage index }\end{array}$ & HCFA data & Psychiatric disorders & $\begin{array}{l}\text { Matching process was validated by testing } \\
\text { the means of pair differences for a set of } \\
\text { market measures, including wage index, } \\
\text { county population, no. of psychiatric } \\
\text { beds in county, age population categories } \\
\text { and total no. of beds }\end{array}$ \\
\hline Sloan et $\mathrm{al}^{12}$ & $\begin{array}{l}\text { All Medicare patients with } 1 \text { of } 4 \text { diagnoses } \\
\text { admitted to a nonfederal, general hospital } \\
\text { with LOS }<92 \text { d who were also included in } \\
\text { Long-Term Care Survey (voluntary national } \\
\text { Medicare survey of patients }>65 \text { yr old with } \\
\geq 1 \text { limitation of ADL or instrumental ADL, } \\
\text { undertaken in } 1982,1984,1989 \text { and } 1994 \text { ) }\end{array}$ & $\begin{array}{l}\text { Medicare claims data } \\
\text { were merged with } \\
\text { National Long-Term } \\
\text { Care Survey data }\end{array}$ & $\begin{array}{l}\text { Hip fracture, stroke, } \\
\text { coronary artery disease, } \\
\text { congestive heart failure }\end{array}$ & $\begin{array}{l}\text { Age, sex, education, ethnicity, marital } \\
\text { status, income, community living, no. of } \\
\text { ADLs, cognitive awareness, bladder/bowel } \\
\text { control, comorbidity, primary diagnosis at } \\
\text { index admission, market characteristics } \\
\text { (population per square mile, Herfindahl } \\
\text { index, Medicare hospital wage index, } \\
\text { HMO market share, hospital beds per } 100 \\
\text { population), year of index admission, no. } \\
\text { of hospital beds and teaching status }\end{array}$ \\
\hline Keeler et $\mathrm{al}^{13}$ & $\begin{array}{l}\text { Non-Medicare patients admitted with } 1 \text { of } \\
10 \text { common medical problems to a } \\
\text { California hospital that submitted } \\
\text { discharge data to the California OSHPD } \\
\text { during 1986, 1989, } 1992 \text { and } 1994 . \\
\text { Excluded hospitals: Kaiser Permanente, } \\
\text { military, specialty, psychiatric, } \\
\text { rehabilitation and long-term care }\end{array}$ & $\begin{array}{l}\text { Annual uniform } \\
\text { discharge data and } \\
\text { hospital disclosure data } \\
\text { from the California } \\
\text { OSHPD }\end{array}$ & $\begin{array}{l}\text { Patients admitted with } \\
1 \text { of } 10 \text { common } \\
\text { medical problems (e.g., } \\
\text { cerebrovascular } \\
\text { disease, pneumonia, } \\
\text { heart failure) }\end{array}$ & $\begin{array}{l}\text { Patient characteristics, case mix, LOS, } \\
\text { percentage of admissions in each } \\
\text { hospital covered by Medicare/Medicaid, } \\
\text { capital ratio (total assets / total operating } \\
\text { expenses), teaching status, county level } \\
\text { measures (e.g., population per square } \\
\text { mile, per capita income in 1988), } \\
\text { Medicare prospective payment system } \\
\text { wage price index, Herfindahl- } \\
\text { Hirschman Index, year and no. of } \\
\text { admissions }\end{array}$ \\
\hline McCue et $\mathrm{al}^{14}$ & $\begin{array}{l}\text { HCFA Minimum Cost Data Set was used } \\
\text { to select } 2 \text { sample groups (existing and } \\
\text { new rehabilitation hospitals), which } \\
\text { differed in the establishment of their target } \\
\text { reimbursement level under TEFRA }\end{array}$ & HCFA data & No restriction & Case mix \\
\hline
\end{tabular}

Note: HFC = Health Facilities Commission, HCFA = Health Care Financing Administration, HCA = Hospital Corporation of America, a private for-profit company, OSHPD = Office of Statewide Health Planning and Development, LOS = length of stay, ADL = activity of daily living, HMO = Health Maintenance Organization, TEFRA = Tax Equity and Fiscal Responsibility Act.

*The studies are in chronological order by midpoint of the data collection period. 
tion), year of index admission, number of hospital beds and hospital teaching status. ${ }^{12}$

Another limitation of our systematic review was that we were unable to include 6 studies because the investigators failed to provide an estimate of variance, 3 studies because the investigators either no longer had the data or could not rerun their analyses to remove the public notfor-profit hospitals, and 1 study because the investigators had only charges and not payment data. All 10 of these studies, however, showed higher payments or charges for care at private for-profit hospitals than at not-for-profit hospitals, and in 6 of the 10, the differences were statistically significant.

Our pooled analysis showed significant variability in the direction and magnitude of effect among the studies. It is common practice to pool results with significant heterogeneity, but one may question the advisability of doing so. Although the inference that private for-profit hospitals result in higher payments for care is secure, heterogeneity in results suggests that the magnitude of the effect may differ according to circumstances. In the presence of unexplained heterogeneity, inferences associated with pooled estimates are weaker; nonetheless, these estimates provide the best available estimate of the average effect. ${ }^{25} \mathrm{We}$ present these results as we believe they constitute useful information for decision-makers.

Our pooled analysis and 5 of the studies included in our systematic review demonstrated statistically significant higher payments for care at private for-profit hospitals than at private not-for-profit hospitals, whereas only 1 study demonstrated the opposite. ${ }^{8}$ These results are completely consistent with those of studies that we were unable to include because of technical reasons (Table 1). The lone study demonstrating lower payments for care at private forprofit hospitals compared them with hospitals owned by private not-for-profit organizations but run by a private for-profit firm. ${ }^{8}$ In essence, this is a comparison between different modes of for-profit management.

Why would private for-profit hospitals have higher payments for care than private not-for-profit hospitals? One potential explanation could be that they are providing superior care. However, our previous meta-analysis involving over 38 million patients demonstrated that private for-profit hospitals have higher risk-adjusted mortality rates. ${ }^{2}$ Our meta-analysis involving over 500000 patients receiving hemodialysis also revealed higher risk-adjusted mortality rates at private for-profit dialysis facilities. ${ }^{26}$

The likely explanation is the necessity to generate revenues to satisfy investors, a requirement absent in private not-for-profit hospitals. Private for-profit hospitals are also burdened with a $6 \%$ absolute increase in the proportion of hospital spending devoted to administration as compared with private not-for-profit hospitals. ${ }^{27}$ Further, executive

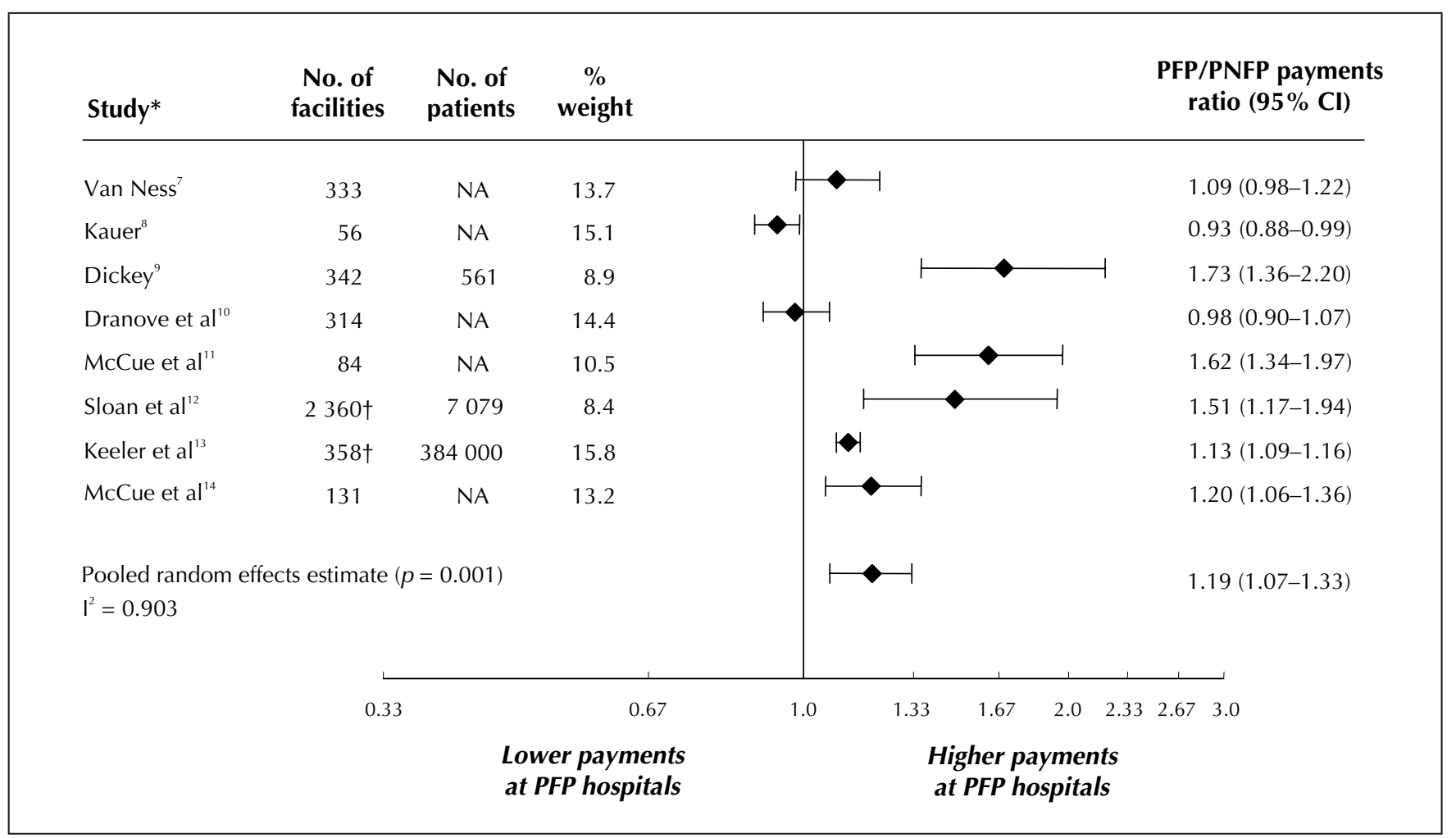

Fig. 2: Relative payments for care at private for-profit (PFP) and private not-for-profit (PNFP) hospitals. Note: $\mathrm{Cl}=$ confidence interval. $*$ The studies are in chronological order by midpoint of the data collection period. †Approximation from investigator. 
bonus incentives are over 20\% higher at private for-profit than at private not-for-profit hospitals. ${ }^{28}$

We offer 2 reasons why our results may actually underestimate the association between private for-profit hospitals and higher payments for care. First, all but 2 of the studies in our systematic review adjusted for case mix. Therefore, our results do not capture any increase in payments for care resulting from inappropriate upcoding of patient diagnoses to enhance reimbursement. Private for-profit hospitals manifest higher upcoding of patient diagnoses than do private not-for-profit hospitals. ${ }^{29}$

Second, the studies in our systematic review did not explicitly address issues of fraud (e.g., performance of unnecessary surgeries, billing for services not provided, inappropriate detainment of psychiatric patients for billing purposes), ${ }^{30}$ which can increase both the direct costs of care and the indirect costs related to investigating and prosecuting offenders. The multimillion-dollar fraud lawsuits in the United States have overwhelmingly been against private for-profit hospitals. ${ }^{31,32}$ It is likely, therefore, that we are underestimating the true association between private for-profit hospitals and higher payments for care.

Many countries, like Canada, are debating choices about private for-profit and private not-for-profit health care delivery. How important is a relative increase in payment for care of $19 \%$ ? Canada currently spends \$120 billion annually on health care, and hospital care accounts for $32 \%$ of overall expenditures. ${ }^{33}$ If we were to convert half of our hospitals to private for-profit institutions, our results suggest that we would pay approximately an extra $\$ 3.6$ billion annually.

Given the differences in the structure of Canadian and US health care systems, one might question the applicability of our results to Canada. The structure of US health care has, however, changed significantly over time (e.g., the introduction of prospective payment systems for Medicare patients and managed health care). The 5 studies that demonstrated statistically significant higher payments for care at private for-profit hospitals included data from 1983 through to the end of 1994, and thus included results from both before and after these changes. Furthermore, these 5 studies had variations in their sources of payments (i.e., Medicare, private insurance or both). These findings suggest that the higher payments for care at private for-profit hospitals are manifest within a variety of health care contexts. Finally, should Canada open the door to private forprofit hospitals, the very same large US hospital chains that have generated the data included in this systematic review will soon be purchasing Canadian private for-profit hospitals. In summary, it is likely that our results are generalizable to the Canadian context.

For-profit hospitals result in both higher mortality rates and greater payments for care than do not-for-profit hospitals. The evidence strongly supports a policy of not-forprofit health care delivery at the hospital level.
This article has been peer reviewed.

From the Department of Medicine (Devereaux, Cook, Guyatt), the Department of Clinical Epidemiology and Biostatistics (Devereaux, Heels-Ansdell, Lacchetti, Haines, Cook, Walter, Bhandari, Lavis, Stoddart, Guyatt), the Faculty of Medicine (Stone), the Department of Surgery (Bhandari), the Department of Political Science (Lavis) and the Centre for Health Economics and Policy Analysis (Stoddart), McMaster University, Hamilton, Ont; the Faculty of Medicine (Ravindran), Inner City Health Research Unit, St. Michael's Hospital, and the Department of Medicine (Bayoumi), Cancer Care Ontario and the Department of Health Policy Management and Evaluation, University of Toronto (Sullivan), and AXON Clinical Research (McDonald), Toronto, Ont.; the Department of Medicine, University of Western Ontario, London, Ont. (Burns); the Department of Medicine, University of Ottawa, Ottawa, Ont. (Patel); the Departments of Medicine and Social and Preventive Medicine, University at Buffalo, Buffalo, NY (Schünemann); the Vancouver Coastal Health Research Institute and the Department of Anesthesia, University of British Columbia, Vancouver, BC (Choi)

Competing interests: None declared.

Contributors: Dr. P.J. Devereaux contributed significantly to the concept and design, data acquisition, data analysis and interpretation of the data. He also wrote the first draft of the manuscript. Ms. Diane Heels-Ansdell and Ms. Christina Lacchetti contributed significantly to the systematic review's concept and design, data acquisition, data analysis and interpretation of the data. Dr. Ted Haines, Dr. Karen Burns, Clinical Clerk Nikila Ravindran, Ms. Heather McDonald, Dr. Rakesh Patel, Dr. Mohit Bhandari, Dr. Holger Schünemann and Dr. Peter Choi contributed significantly to the systematic review's concept and design, data acquisition and interpretation of the data. Dr. S.D. Walter contributed significantly to the data analysis and interpretation of the data. Clinical Clerk Samuel Stone contributed significantly to the systematic review's data acquisition and interpretation of the data. Dr. Deborah Cook, Dr. Ahmed Bayoumi, Dr. John Lavis, Dr. Terrence Sullivan, Dr. Greg Stoddart and Dr. Gordon Guyatt contributed significantly to the systematic review's concept and design and interpretation of the data. All authors provided critical revisions to the manuscript and gave final approval of the submitted manuscript.

Acknowledgements: We wish to acknowledge the outstanding work of Deborah Maddock and Laurel Raftery, who coordinated the study, and Neera Bhatnagar, the librarian who undertook the searches involved in the study. We also thank all the authors of the studies included in our systematic review who confirmed information, provided information and performed additional analyses for our systematic review.

This study was supported by an Atkinson Foundation Research Grant and a Hamilton Health Sciences Research Development Grant. Dr. P.J. Devereaux is supported by a Canadian Institutes of Health Research, Senior Research Fellowship Award. Dr. Karen Burns is supported by a Canadian Lung Association and Merck Frosst Postdoctoral Fellowship Award. Dr. Deborah Cook is a Chair of the Canadian Institutes for Health Research. Dr. Mohit Bhandari is supported by the Detweiller Fellowship from the Royal College of Physicians and Surgeons of Canada, and a Department of Clinical Epidemiology and Biostatistics, McMaster University, Clinical Scientist Fellowship Award. Dr. Peter Choi is supported by a Vancouver Coastal Health Research Institute Mentored Clinician Scientist Award. Dr. Ahmed Bayoumi is supported by a Career Scientist Award from the Ontario HIV Treatment Network. Dr. John Lavis holds a Canada Research Chair in Knowledge Transfer and Uptake.

\section{References}

1. Lewis S, Donaldson C, Mitton C, Currie G. The future of health care in Canada. BM7 2001;323(7318):926-9.

2. Devereaux PJ, Choi PT, Lacchetti C, Weaver B, Schunemann HJ, Haines T, et al. A systematic review and meta-analysis of studies comparing mortality rates of private for-profit and private not-for-profit hospitals. CMA7 2002;166(11):1399-406.

3. Finkler SA. The distinction between cost and charges. Ann Intern Med 1982;96(1):102-9.

4. Fleiss JL. The statistical basis of meta-analysis. Stat Methods Med Res 1993; 2(2):121-45.

5. Higgins JP, Thompson SG, Deeks JJ, Altman DG. Measuring inconsistency in meta-analyses. BM7 2003;327(7414):557-60.

6. Egger M, Smith GD. Misleading meta-analysis. BMf 1995;310(6982):752-4.

7. Van Ness K. Hospitals as business: profits, pricing and productivity in investor-owned and not-for-profit multihospital systems in California [dissertation]. Los Angeles: University of California; 1986.

8. Kauer R. Hospital ownership and performance [PhD thesis]. Cleveland: Case Western Reserve University; 1988.

9. Dickey B. A comparison of for-profit and not-for-profit hospitals on the cost of mental health admissions. Harv Rev Psychiatry 1994;2(2):97-103.

10. Dranove D, White WD. Medicaid-dependent hospitals and their patients: How have they fared? Health Serv Res 1998;33(2 Pt 1):163-85. 
11. McCue MJ, Clement JP. Relative performance of for-profit psychiatric hospitals in investor-owned systems and nonprofit psychiatric hospitals. Am 7 Psychiatry 1993;150(1):77-82.

12. Sloan FA, Picone GA, Taylor DH, Chou SY. Hospital ownership and cost and quality of care: Is there a dime's worth of difference? 7 Health Econ 2001;20(1):1-21.

13. Keeler EB, Melnick G, Zwanziger J. The changing effects of competition on nonprofit and for-profit hospital pricing behavior. F Health Econ 1999;18(1):69-86.

14. McCue MJ, Thompson JM. The ownership difference in relative performance of rehabilitation specialty hospitals. Arch Phys Med Rebabil $1995 ; 76(5): 413-8$

15. Lewin LS, Derzon RA, Margulies R. Investor-owneds and nonprofits differ in economic performance. Hospitals 1981;55(13):52-8.

16. Renn SC, Schramm CJ, Watt JM, Derzon RA. The effects of ownership and system affiliation on the economic performance of hospitals. Inquiry 1985;22(3):219-36.

17. Sorrentino EA. Hospitals vary by LOS, charges, reimbursements and death rates. Nurs Manage 1989;20(1):54-6,58,60.

18. Phijaisanit $W$, Phijaisanit P, Boonyaratapan P, Thirapat C, Siripanich B, Papasratorn T. Investor-owned and not-for-profit hospitals. A comparison study in Bangkok, 1981. 7 Med Assoc Thai 1985;68(6):293-7.

19. Sloan FA, Vraciu R. Investor-owned and not-for-profit hospitals: addressing some issues. Health Affairs 1983;2:25-37.

20. Pattison RV, Katz HM. Investor-owned and not-for-profit hospitals. A comparison based on California data. N Engl f Med 1983;309(6):347-53.

21. Silverman EM, Skinner JS, Fisher ES. The association between for-profit hospital ownership and increased Medicare spending. $N$ Engl 7 Med 1999;341(6):420-6

22. Watt JM, Derzon RA, Renn SC, Schramm CJ, Hahn JS, Pillari GD. The comparative economic performance of investor-owned chain and not-forprofit hospitals. N Engl 7 Med 1986;314(2):89-96.

23. Friesner DL, Rosenman R. Cost shifting revisited: the case of service intensity. Health Care Manag Sci 2002;5(1):15-24.

24. Meurer JR, Kuhn EM, George V, Yauck JS, Layde PM. Charges for childhood asthma by hospital characteristics. Pediatrics 1998;102(6):e70 [full-text electronic article].

25. Montori V, Hatala R, Guyatt GH. Evaluating differences in study results. In: Guyatt G, Rennie D, editors. The Users' guide to the medical literature: a manual for evidence-based clinical practice. Chicago: AMA publications; 2002

26. Devereaux PJ, Schunemann HJ, Ravindran N, Bhandari M, Garg AX, Choi PT, et al. Comparison of mortality between private for-profit and private notfor-profit hemodialysis centers: a systematic review and meta-analysis. $7 A M A$ 2002;288(19):2449-57.

27. Woolhandler S, Himmelstein DU. Costs of care and administration at for-profit and other hospitals in the United States. N Engl 7 Med 1997;336(11):769-74.

28. Eichenwald K, Gottlieb M. Health care's giant: when hospitals play hardball; a hospital chain's brass knuckles, and the backlash. New York Times; 1997 May $11 ; \mathrm{C} 1$.

29. Silverman E, Skinner J. Are for-profit hospitals really different? Medicare upcoding and market structure. Cambridge, MA: National Bureau of Economic Research; 2001.

30. Eichenwald K. \$100 Million settlement seen in Tenet suits. New York Times; 1997 July 30;D1.

31. Guyatt G. Fraud is part of for-profit health care. Hamilton Spectator; 2003 March 21.
32. Woolhandler S, Himmelstein DU. When money is the mission: the high costs of investor-owned care. N Engl 7 Med 1999;341(6):444-6.

33. Guyatt G, Yalnizyan A, Devereaux PJ. Solving the public health care sustainability puzzle [editorial]. CMA7 2002;167(1):36-8.

Correspondence to: Dr. P.J. Devereaux, McMaster University, Faculty of Health Sciences, Department of Clinical Epidemiology and Biostatistics, Rm. 2C8, 1200 Main St. W, Hamilton ON L8N 3Z5; fax 905 526-1353; philipj@mcmaster.ca

2004 W ORKS HOP SCHEDULE
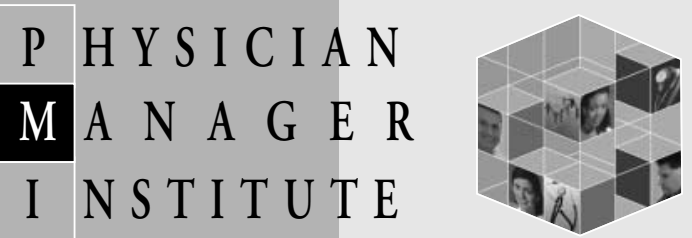

A five level credit program exclusively for physicians designed to develop superior leadership and management skills

Approved for RCPSC, CFPC, CCHSE credits

PMII/II

Sept. 26-28 / Sept. 29-0ct. 1

Calgary, AB

PMI III/IV

Nov. 7-9 / Nov. 10-12

Vancouver, BC

PMI Refresher

Oct. 22-24

Vancouver, BC

In-house PMI

A practical, cost effective and foc used training opportunity held on-site for medical leaders and managers

FOR INFORMATION:

tel $800663-7336$ or $613731-8610$

X2319 (PMI) or X2261 (In-house PMI)

professional_development@cma.ca

che.ce 